\title{
From Culture 2.0 to a Network State of Mind: A Selective History of Web 2.0's Axiologies and a Lesson from It
}

\author{
Pak-Hang Wong
}

\author{
Institute for Science, Innovation and Society, University of Oxford \& Oxford Uehiro Centre for \\ Practical Ethics, University of Oxford, United Kingdom, pak.wong@insis.ox.ac.uk, \\ www.wongpakhang.com
}

\begin{abstract}
There is never a shortage of celebratory and condemnatory popular discourse on digital media even in its early days. This, of course, is also true of the advent of Web 2.0. In this article, I shall argue that normative analyses of digital media should not take lightly the popular discourse, as it can deepen our understanding of the normative and axiological foundation(s) of our judgements towards digital media. Looking at some of the most representative examples available, I examine the latest wave of popular discourse on digital media, focusing on the (new) worries and doubts voiced by the alarmists and the (new) hopes and dreams portrayed by the enthusiasts. I shall illustrate that various stances in the popular discourse on Web 2.0 are ultimately rested on different notions of the self. This conclusion entails an important lesson for our practice of critiques of digital media, as it entails that our critiques of digital media cannot be done without referring to a notion of the self. Hence, a normative enquiry of digital media should not only be about the moral and/or prudential goodness or badness per se; it should be about who we should be online, or which notion(s) of the self we should strive for.
\end{abstract}

Keywords: Self, Popular Discourse, Digital Media, Good Life, Axiology, Web 2.0, Information Ethics, Andrew Keen, Clay Shirky, Nicholas Carr, Sherry Turkle, Jaron Lanier, Nick Bilton, Charles Ess

Acknowledgement: This article is derived from my doctoral dissertation "Net Recommendation: Prudential Appraisals of Digital Media and the Good Life." Parts of this paper were presented at "Critique, Democracy and Philosophy in 21st Century Information Society. Towards Critical Theories of Social Media." I want to thank the audiences for their useful feedbacks and suggestions, and I would also like to thank the two anonymous referees for their valuable comments.

There is never a shortage of celebratory and condemnatory popular discourse about the Internet-even in its early days. ${ }^{1}$ Yet, the popular discourse was quieted as the hopes and dreams of the Internet have faded with the burst of the dot-com bubble in the 1990s and the rise of control and surveillance over and through ICTs after September 11, 2001 (Lovink 2011/2003, 5-7). The advent of Web 2.0, with its newly proclaimed potential and promise, however, has rejuvenated the hopes and dreams of enthusiasts of the Internet and has renewed the popular discourse. Looking at some of the most representative examples available, this article aims to examine this (new) wave of popular discourse, focusing on the (new) worries and doubts voiced by the alarmists and the (new) hopes and dreams portrayed by the enthusiasts.

Here, I examine the axiologisation (i.e. what benefits and harms are being foregrounded) and problem representation (i.e. what and how problems are being represented) of Web 2.0 in popular discourse. ${ }^{2}$ My analysis aims to disclose what values are being employed in support of and/or against Web 2.0, and, in turn, to unveil the normative and axiological foundations of various popular judgements of Web 2.0. Of course, there is a wide range of methods for analysing actual discourse, but I will not align my analysis with a specific method for analysis in this article; ${ }^{3}$ instead, I will analyse the popular judgements from a philosophical-hermeneutical perspective with a close (re)reading of the popular discourse. Particularly, my analysis is guided by the idea of sensemaking, i.e. why and how a judgement makes sense to us at all? In other words, I attempt to show why, and how, a popular judgement of Web 2.0 can be taken by a person as plausible and/or sensible. Alternatively, I attempt to demonstrate here what normative and axiological foundations a person has to hold for a popular judgement to be considered as plausible and/or sensible. In doing

\footnotetext{
${ }^{1}$ For an overview of the popular discourse on digital media and various normative positions in the popular discourse, see Thierer (2011)

${ }_{2}^{2}$ In this article, I shall use the term 'Web', 'Web 2.0', 'the Internet' and other similar terms interchangeably. While I acknowledge that 'Web', 'Web 2.0' and 'the Internet' might be used to refer to different things in a different technical and/or theoretical context (see, e.g. Fuchs et al. 2010), as the works I analyse in this article use them interchangeably to refer to a (network) platform that is distinguished by its participatory nature, with immediacy, dynamic content, openness and collaborativeness as its key characteristics and features (Beers \& Burrows 2007), I shall follow the usage of those terms in the works.

${ }^{3}$ For an overview of various approaches and methods of discourse analysis, see Glynos et al. (2009).
} 
so, I uncover different normative and axiological grounds for different evaluative stances towards Web 2.0.

There is a vast amount of popular works, either in print or online, on the (potential) impacts of Web 2.0. My objective is not to recount all accounts of Web 2.0 presented in this large and still burgeoning amount of works, which will hardly be manageable. Hence, my objective is to offer a (re)interpretation of the popular discourse on Web 2.0 with a number of representative examples, and to disclose the views of the good life and the notions of the self underline them. In doing so, I hope I can, at the same time, uncover the normative and axiological grounds of various popular judgements of Web 2.0. This is important, I think, as uncovering their normative and axiological grounds is essential to our critiques of digital media, especially if we want our critiques to be practical. In short, this article is, at the same time, interpretative, critical, and constructive: it is interpretative because it offers a (re)interpretation of various popular judgements of Web 2.0; and, it is critical and constructive because it draws from the (re)interpretation to highlight an oft-missed piece in our critiques of Web 2.0-and, more generally, in our critiques of digital media-that renders them incomplete and insufficient; but, this article also tries to reorient researchers to this oft-missed piece and to suggest how our critiques ought to be practised.

In Section 1 "Enemies and Friends of Culture 2.0", I examine Andrew Keen's and Clay Shirky's views on the socio-cultural impacts of Web 2.0, and I show that their diverging views on Web 2.0's socio-cultural impacts are ultimately grounded in different ways to understand the self. In Section 2 "Vices and Virtues of a Network State of Mind", I look at the discussions on Web 2.0's impacts on our interior lives (i.e. brain, mind, cognition, selfhood, etc.). More specifically, I examine the views of Nicholas Carr, Sherry Turkle, Jaron Lanier and Nick Bilton. Again, I discern various notions of the self that enable us to make sense of their standpoints. Finally, in Section 3, I turn to an important lesson that can be drawn from my (re)interpretation of the popular discourse, namely we cannot determine the goodness (or badness) of digital media without referring to some notions of the self. Accordingly, I argue that we have to reconceptualise our critiques of digital media in terms of who we should be online, or which notion(s) of the self we should strive for.

\section{Enemies and Friends of Culture $\mathbf{2 . 0}$}

My point of entry into the analysis is Andrew Keen's (in)famous The Cult of Amateur: How Today's Internet is Killing Our Culture (2007). Keen's book is especially suitable as the point of entry not only because it is arguably the first book-length critique of Web 2.0, it is also because the book has generated an enormous amount of positive and negative responses from proponents and detractors of Web 2.0. In this regards, the reception of Keen's book should qualify it as a window to one major standpoint on Web 2.0. After analysing Keen's view, I turn to an equally prominent view on Web 2.0 presented by Clay Shirky. In many ways, Shirky's celebratory attitude on Web 2.0 presents a flip side of Keen's condemnatory attitude. As such, Shirky's and Keen's views offer a useful contrast between two major views on the socio-cultural impacts of Web 2.0.

\subsection{Web 2.0, the Enlightenment's Nightmare?}

The Cult of Amateur is a wholesale assault on Web 2.0 and the purported Web 2.0 culture and ethos, which Keen believes (will) have "destructive impact" on "culture, economy and [moral] values" (Keen 2007, 1). The culprits of cultural, economic and moral demises in Keen's criticism of Web 2.0 are the "democratisation of media" and "noble amateurs", as he believes that they will-if they have not already - come to displace the "traditional cultural institutions" and "experts and cultural gatekeepers". According to Keen, by providing users the means of production and distribution of text, music and video that are originally in the hands of a limited number of cultural institutions, Web 2.0 has enabled the "noble amateur", i.e. "a hobbyist, [...] someone who does not make a living from his field of interest, a layperson, lacking credentials, a dabbler" (Keen 2007, 36), to create and distribute free, self-made content. And, whereas the democratisation of media has taken away the traditional cultural institutions' vantage positions to control, regulate and filter information, the proliferation of amateur content and celebration of amateurism have crowded out expert's judgements and the importance of expertise (see, Keen 2007, Chapter $1 \& 2$ ). ${ }^{4}$ In short, Keen's criticism of Web 2.0 is a criticism of Web 2.0's participatory nature and the new role of users as active content creators.

\footnotetext{
${ }^{4}$ Keen has also criticised other aspects of the Internet, e.g. piracy, intellectual property and plagiarism (Keen 2007 , Chapter 4, 5 \& 6, esp. 141-145), privacy and (participatory) surveillance (Keen 2007, Chapter 7), pornography (and sex) and gambling online and Internet addiction (Keen 2007, Chapter 6, esp. 146-165). Pace Keen, I do not think these issues are unique to Web 2.0. Hence, I will not examine his discussion of those issues here.
} 
The question remains is that even if it is true that there is a disempowerment of traditional cultural institutions and a decline in the importance of experts and their expertise, what is wrong (and/or bad) about them? To answer this question, we have to understand how Keen conceives traditional cultural institutions and experts. For him, traditional cultural institutions are specific systems of content-or, more accurately, knowledge-production and distribution, which are characterised by rigorous review processes and standards; and, in turn, the review processes and standards are carried out and enforced by experts (with their expertise). Moreover, expertise can only be acquired through extensive education and training made possible by traditional cultural institutions. So construed, in Keen's view, traditional cultural institutions and experts (and their expertise) are mutually dependent on each other (Keen 2007, Chapter 2).

Following this line of thought, Keen argues that the vice of Web 2.0 is a degradation of truth and trust. He claims that it is difficult to find truth on Web 2.0 because "in a flattened, editor-free world where [amateurs] can post their amateurish creations at will, and no [expert] is being paid to check their credentials or evaluate their material, media is vulnerable to untrustworthy content of every strip." (Keen 2007, 19) In other words, his claim is that Web 2.0 lacks review processes and standards carried out and enforced by traditional cultural institutions and the experts they house, which are required for acquisition of truth (or, acquisition of knowledge) (Keen 2007, Chapter 2 \& 3). In the same vein, Keen laments the aggregation of users' (or, more precisely, amateurs') preferences and opinions through computational algorithms has come to replace traditional cultural institutions' review processes and standards as well as expert's judgements, and he believes the former is easily manipulable and unbalanced (Keen 2007, 92-96).

Keen also claims that democratisation of media and amateurism have resulted in a problem of trust because Web 2.0 allows users to produce and distribute content anonymously, which makes it difficult-if not impossible - to verify its sources. Or, conversely, the content produced and distributed anonymously hardly requires supports because of its lack of verifiability (Keen 2007, 65-75). In other words, anonymity allows users to run free from moral responsibility and legal liability (Keen 2007, 71-83). A similar argument is offered by Keen for arguing against the practices of "remixes" and "mash-ups" on Web 2.0, too. In a nutshell, he argues that remixing and mashing-up content have destroyed the idea of authorship and integrity of works by encouraging fragmentation of authorship and works (Keen 2007, 23-26, 57-60).

Keen's book has been thoroughly scrutinised by a number of commentators. For instance, Lawrence Lessig (2007) has argued that his book has suffered from numerous factual, interpretative and conceptual errors. Although the commentators of Keen's book may well be right in their criticisms, I am not interested in assessing Keen's book as such; as I have noted in the beginning of this article, my aim is to make sense of his criticism of Web 2.0 by uncovering the normative and axiological ground needed for it to be taken as sensible and/or plausible. Hence, I shall set aside those questions concerning its empirical and theoretical plausibility, and focus on the values he employs in his criticism.

It is not too difficult to see what values are at work in Keen's criticism of Web 2.0. His defence of traditional cultural institutions' review processes and standards and experts and expertise acquired through extensive education and training aligns his criticism with the Enlightenment's belief in the supremacy of scientific rationality. However, I think his criticism of Web 2.0 can still be better understood by (re)contextualising it via the image of the disengaged self. ${ }^{5}$ I borrow the notion of the disengaged self from philosopher Charles Taylor, who forcefully illustrated that this notion of the self emerged from the ideal(s) of the Enlightenment, and it is characterised by the disengagement stance exemplified by scientific empiricism, the primacy of instrumental reason and an accompanied procedural conception of reason (Taylor 1989). This notion of the self portrays its ideal as an autonomous, rational being, who is self-determining and self-responsible, and whose acts ought to be determined by reason and reason alone.

In this regards, Keen's defence of traditional cultural institutions as well as experts and their expertise against democratisation of media and amateurism is a clear instance of championing (scientific) empiricism: neither user-generated content nor aggregation of users' preferences and opinions qualify as truth (or knowledge) because they fall short of the standards set by scientific practices as they are conventionally understood, i.e. clarity and distinctness. Alternatively, we can also view Keen's defence of experts as a defence of individual rationality in opposition to irrationality of the collective. In his account, experts are intellectual heroes who have access to truth and standards; they are heroic, because expertise is acquired through an individual's hard work in education

\footnotetext{
${ }^{5}$ I have discussed Taylor's notion of the disengaged self and its relevance to normative analysis of digital media in more detail elsewhere, see Wong (2010).
} 
and training (i.e. self-disciplining). Expertise, in other words, is an individual's intellectual achievement as well as a manifestation of individual rationality par excellence.

On the other hand, Keen's criticism of anonymity and the failure of trust in Web 2.0 can also be better understood through the image of the disengaged self. Anonymity is wrong and bad because it offers an escape from moral responsibility and legal liability. With anonymity and fake identities on Web 2.0, people can act without assenting to their decisions and actions. However, the possibility of a person acting without assenting to his own decisions and actions goes against the core of the disengaged self, namely the idea of being an autonomous subject, i.e. a subject who is (self-)responsible and (self-)disciplined because of his own will; and, the same is true to his criticism of "remix" and "mash-ups", too. As his idea of author is a person who is, and can be, held responsible and accountable for the works he has produced. In short, for Keen and the view he represents, Web 2.0 is problematic because it fosters a class of sub-rational people (i.e. with the disappearance of traditional cultural institutions and experts) and non-autonomous subjects (i.e. with the withholding of moral responsibility through anonymity and fake identities) that run against the very ideal of the disengaged self.

\subsection{Web 2.0 and the (Post-)Enlightenment Dream}

In a sharp contrast to the condemnatory attitude towards Web 2.0 (re)presented by Keen, there is another camp of proponents who champion Web 2.0's revolutionary potential and promise, especially its participatory nature and the new role of users as active content creators. They have published a number of "manifestoes" to demonstrate Web 2.0's potential and promise, most notable among them are Yochai Benkler's Wealth of Networks: How Social Production Transform Market and Freedom (2006), Don Tapscott and Anthony D. Williams's Wikinomics: How Mass Collaboration Changes Everything (2006) and Macrowikinomics: Rebooting Business and the World (2010), Charles Leadbeater's We-Think (2008), and Clay Shirky's Here Comes Everybody: How Change Happens When People Come Together ${ }^{6}$ (2009) and Cognitive Surplus: Creativity and Generosity in a Connected Age (2010). ${ }^{7}$ In this section, I focus on the two books by Shirky. My choice of Shirky's books over the others is based on the subject of Shirky's books, i.e. impacts of Web 2.0 on society in general, and Shirky's visibility and popularity among the general public-as one reviewer of Cognitive Surplus writes, "Clay Shirky is the Internet's most prominent ponderer [...] Every six weeks or so the New York Times quotes Shirky in stories [...]" (Last 2010). Shirky, I believe, is a suitable example of the celebratory attitude towards Web 2.0.

Here Comes Everybody and Cognitive Surplus are parts of Shirky's larger project to illustrate the revolutionary potential and promise of Web 2.0. The two books, as Shirky himself notes, are written with two different agendas in mind: whereas the first book is "about the rise of social media as a historical fact, and the changed circumstances for group action [...]", the second book discusses "free time [as] a [new] shared global resource" made possible by social media and how to "take advantage of that resource" (Shirky 2010, 27). In this respect, Here Comes Everybody is mainly descriptive, i.e. it aims to describe what is of value in social media, while Cognitive Surplus can be viewed as normative in that it recommends specific ways to design and use social media to realise certain ends.

The running argument of Here Comes Everybody is a simple one: Web 2.0 (or, social media), as a set of new communication tools, has lowered the socioeconomic cost of sharing, cooperation and collective action, and it has led to new ways of organising and running our society, such as "post-managerial organisation[s]" (Shirky 2009, 41), a disappearance of "professional categories" (Shirky 2009, 70), a new system of (cultural) production based on "publish-then-filter" (Shirky 2009, 81), an "unmanaged division of labour" (Shirky 2009, 117) and a replacement of "planning with coordination" (Shirky 2009, 178), etc. The new ways of organising and running society, as Shirky argues, are beneficial to both individuals and the society. For individuals, social media has increased freedom - in both negative and positive sense: individuals are free from management, (professional) authority and plan, and they are also free to participate, express (through publishing and producing content) and experiment. For the society, social media has helped to resolve social

\footnotetext{
${ }^{6}$ This title is first published in 2008 with the title Here Comes Everybody: The Power of Organizing without Organizations, and an updated edition with a new chapter is later published in 2009. The page numbers in here refer to the pages numbers of the updated edition.

${ }^{7}$ Some have criticised these manifestoes for equivocating non-profit and profit-oriented (user-)production, thereby legitimatising an expansion of capitalism into the social, cultural and political dimensions of our lives, see, e.g. van Dijck \& Nieborg (2009). While I agree that this line of criticism is important to normative analysis of Web 2.0 , my main goal here is only to examine the normative grounds of the judgements.
} 
dilemmas through connecting individuals, and it has made available the untapped resources, which are unavailable to people who are unconnected previously.

In Cognitive Surplus, Shirky rehearses most of the points he has made in the earlier book, especially his claim that social media has allowed an increase in both negative and positive freedom. However, his emphasis in Cognitive Surplus has shifted to positive freedom, i.e. what individuals can do-or, what individuals can do with the free time-in the context of the new degree of connectedness afforded by social media. The crux of Shirky's argument is that using free time for passive consumption is excusable only insofar as the socioeconomic cost of its alternatives is too high for individuals, but with the socioeconomic cost of active participation being lowered tremendously by social media, passive consumption should no longer be the norm for using free time (Shirky $2010,10-12$ ). To highlight the potential of active participation, Shirky asks his readers to "imagine treating the free time [...] as an aggregate, a kind of cognitive surplus" (Shirky 2010, 9) that "can be harnessed for large, communally created project, rather than as a set of individual minutes to be whiled away one person at a time" (Shirky 2010, 10). He argues that active participation, in effect, is a manifestation and realisation of people's sense of autonomy and competence at the personal level and their sense of membership and generosity at the societal level (Shirky 2010, Chapter 3); and, active participation is also a source of personal, communal, public and civic values, which passive consumption is not (Shirky 2010, Chapter 6). In short, Shirky offers an argument against passivity and in favour of (inter)activity. In Shirky's view, being (inter)active has become an imperative; or, to put it differently, an imperative to participate (through producing) and to share has come into being along with the rise of social media.

Shirky's praise of social media's capacity to increase freedom is seemingly derived from the ideal of the disengaged self, i.e. a notion of the self which prioritises autonomy. His celebratory note on the new positive freedom, i.e. the capability to participate (through producing) and to share in every individual, too suggests an invocation of the value of equality: every individual is equal with respect to their opportunity to participate and share, which, again, seems to show that the normative and axiological foundation of his view is based on the image of the disengaged self. However, I contend that the image of the disengaged self cannot make sense of (i) Shirky's positive attitude towards the unorganised (or the disorganised), the rejection of professional authority (as in Keen's understanding), and improvisation, and, more importantly, (ii) the imperative of (inter)activity (or, the imperative to participate and to share)

It should be relatively straightforward why the image of the disengaged self cannot ground Shirky's positive attitude towards the unorganised, the rejection of professional authority, and improvisation. Although the disengaged self prioritises autonomy, autonomy is valuable insofar as it is restrained by self-discipline. However, the unorganised (or disorganisation), the rejection of professional authority, and improvisation imply a devaluing of self-discipline. Of course, certain degree of (self-)discipline must be involved in performing any activities, be they managed or unorganised, governed or ungoverned by authority, or planned or improvised. Yet, (self-)discipline in the latter types of actions (i.e. unorganised/disorganised, ungoverned by authority, and improvised acts) are not (self-)discipline in the strong, rational sense required by the disengaged self; they are (self-)discipline only in a weak sense that those activities are willingly engaged; they are only performed by a person spontaneously without his (rational) commitment to them. Moreover, Shirky's plea for the unorganised/disorganised, the rejection of authority, and improvisation presumes a fluid worldview, which is ultimately incompatible to the stable worldview required by the image of the disengaged self.

In a similar vein, the disengaged self cannot make sense of the imperative of (inter)activity because (inter)activity (or, participation and sharing) cannot be viewed as an imperative from the perspective of the disengaged self. It is indeed true that participation and sharing are valuable from the perspective of the disengaged self, e.g. Kant, one of the key Enlightenment thinkers, whose ideas resonated strongly with the idea of the disengaged self, argued that exchanges of well-reasoned thoughts through participation and sharing in the public sphere are necessary for universal enlightenment (Frick \& Oberprantacher 2011, 18-19). However, the argument for participation and sharing from this point of view can only be negative, i.e. it can only be an argument for a right to participate and to share, and for the condition(s) for participation and sharing. In other words, from the perspective of the disengaged self, insofar as every act is an act of and by autonomous beings, there cannot be any obligation for them to participate and to share actively, as they cannot be (morally) coerced into participation and sharing. This point, perhaps, is best illustrated by putting alongside 
the idea of sharing and charity: sharing is viewed as an act of charity precisely because there is no obligation for individuals to share. ${ }^{8}$

Now, I think the notion of the reflexive self from Giddens and Beck et al. enables us to make better sense of Shirky's judgement and the attitude behind it. ${ }^{9}$ The reflexive self emerges from the radicalised condition of modernity, i.e. the (radical) separation of time and space, the (radical) disembedding, and the (radical) reflexive appropriation of knowledge (Giddens 1990, Chapter 2). Under the late modern condition, "social practices are constantly examined and re-formed in light of incoming information about those very practices, thus constitutively altering their character... What is characteristic of [late] modernity is not an embracing of the new for its own sake, but the presumption of wholesale reflexivity-which of course includes reflection upon the nature of reflection itself" (Giddens 1990, pp. 38-39). In short, inherent to the reflexive self is a radicalised reflexivity that challenges certainty and any standardised criteria, and it compels individuals to choose active$l y$ in accordance to their own will with respect to their own situations. Accordingly, self-discipline is replaced by spontaneous self-choice in the reflexive self, which should help to explain why Shirky's plea for the unorganised/disorganised, the rejection of authority, and improvisation could be viewed as plausible and sensible. Similarly, the reflexive self's acceptance of fluidity through its challenge to certainty and standardised criteria should also help to explain the fluid worldview presumed by Shirky in his view. Indeed, as the term 'reflexive' in the reflexive self implies, rational deliberationthe cornerstone of the disengaged self-is no longer prized in the reflexive self, instead what matters is a person's ability to intuitively and instantaneously cope with the unorganised/disorganised, the ungoverned, and the unexpected, i.e. the reflex.

Shirky's imperative of (inter)activity, therefore, can be better understood with a rereading through the late modern self, and Beck et al.'s notion of quasi-subject is particularly useful. The reflexive self, as a quasi-subject, is "a constitutive part of a context that determines its subjectivity, and within which exercises joint decision-making power" (Beck et al. 2003, 26). Accordingly, individuals, as quasi-subjects, do not exhaustively determine their subjectivity; at the same time, because of the redistribution of their (quasi-)subjectivity over their networks, which, in turn, are connected to others' networks, individuals' decisions and actions have become a constitutive parts of others' subjectivity, too. The redistribution of (quasi-)subjectivity over the networks implies that every action is no longer an action only of and by individuals themselves, but of and by the networks they are connected to. As such, realisations of any decisions and actions are dependent on others' (quasi-)subjectivity as well. It thus entails a new obligation for individuals to involve actively in their networks, because they are mutually dependent within their networks. So construed, the imperative of (inter)activity can be reinterpreted as an explicit formulation of the norm of quasisubjectivity.

In short, the different views of Web 2.0 (re)presented by Shirky and Keen can be traced back to the different normative and axiological foundations their views are based on. For Shirky (and the view he represents), the basis of the positive judgements towards Web 2.0 comes from the reflexive self, which accepts fluidity and uncertainty of any foundation and sees individuals as quasisubjects, who are obliged to involve actively because of the mutual dependence inscribed by the logic of the networks. For Keen (and the view he represents), the basis of the negative judgements comes from the disengaged self, in particular, the idea of subjects as autonomous, rational beings prescribed by it.

\section{Vices and Virtues of a Network State of Mind}

Like Keen's The Cult of Amateur and Shirky's Here Comes Everybody and Cognitive Surplus, early discussions of Web 2.0 mainly focus on Web 2.0's impacts on the society-at-large. However, as Geert Lovink rightly noted, recent popular discourse on Web 2.0 has taken a "neurological turn" (Lovink 2010). The "neurological turn" can be viewed as an interiorisation of the concerns over Web 2.0, namely Web 2.0 does not only affect people's exterior lives, e.g. their society and culture, it also affects their interior lives, i.e. their brain, mind, cognition, selfhood, etc. In this section, I examine four examples that have taken the "neurological turn", and I shall again uncover their normative and axiological foundations. More specifically, I look at the views of Nicholas Carr, Sherry Turkle, Jaron Lanier and Nick Bilton, who have different takes-either negative (i.e. Carr, Turkle

\footnotetext{
${ }^{8}$ Also, see Turkle (2011). Although Turkle's focus is on intimacy, her point is instructive. She notes that in the "[t]raditional views [...] autonomy and strong personal boundaries [are] reliable signs of a successfully maturing self. [...] [W]e work toward an independent self capable of having a feeling, considering it, and deciding whether to share it. Sharing a feeling is a deliberate act, a movement toward intimacy" (Turkle 2011, 174-175; my emphasis).

${ }^{9}$ For a discussion of the notion of the reflexive self, see Giddens (1991), Beck \& Beck-Gernsheim (2002), and Beck et al. (2003).
} 
and Lanier) or positive (i.e. Bilton)—on the changes in people's interior lives brought by Web 2.0, and show which notions of the self are behind their views.

\subsection{Cognitively and Emotionally Shallow Minds}

Nicholas Carr's "Is Google Making Us Stupid" (2008) is arguably the first article in the "neurological turn". He has later expanded his ideas into the book The Shallow: What the Internet is Doing to Our Brain (Carr 2010). In the book (and the earlier article), Carr laments that the current Internet (i.e. Web 2.0), with its defining characteristics, i.e. interactivity, hyperlinking, searchability and multimedia, has detrimentally affected our habits of reading, writing, and thinking. He argues that our ability to have "sustained, unbroken attention to a single, static object" (Carr 2010, 64)-a prerequisite for deep reading and deep thinking-has become difficult, if not impossible, with the habitual use of the Internet. According to Carr, reading on screen with scrolling and clicking is phenomenologically different from reading on paper, and the differences between them have a direct impact on our attentiveness. At the same time, he argues that hyperlinking does not merely offer readers supplementary information, but it draws them away from the text they are reading and directs them to other (not so) relevant pieces of information. The same is true for searchability of digitised texts too, or so he argues. Digitised (and thus searchable) texts enable non-linear reading and allow readers to see a text in and as fragments but not as a coherent, unified narrative. Finally, being a simultaneous medium of various types of information, the Internet has further weakened our ability to focus on and attend to the content of a text-if it is still sensible to say there is the content at all (Carr 2010, 89-92). In short, Carr's criticism is one against a particular kind of mind (or type of cognition) moulded by the Internet, i.e. an inattentive, shallow mind.

Carr's criticism, in effect, is targeted against the notion of the reflexive self. As I have noted, the reflexive self downplays the ability of rational deliberation and prizes the ability to respond intuitively and instantaneously. Here, the ability to skim with scrolling and clicking-instead of immersing into a text through deep reading and deep thinking - and the ability to jump from one place to another with hints of hyperlinks and search results both within and outside a text are clear instances of reflexive actions valued by the reflexive self. Similarly, Carr's worry over the fragmentation of text is also based on the assumption that fluidity-something the reflexive self accepts without qualms-is problematic. ${ }^{10}$ In this respect, Carr's criticism is essentially against the reflexive self, which, in his account, will inevitably be inattentive and shallow.

Still, the question remains: why are deep reading and deep thinking valuable at all? Here, Carr's description of deep reading (and deep thinking) is illuminating,

"What is so remarkable about [reading] was that the deep concentration was combined highly active and efficient deciphering of text and interpretation of meaning, [deep reading] was valuable not just for the knowledge readers acquired from the author's words but for the way those words set off intellectual vibrations within their own mind. [...] [i.e.] people made their own associations, drew their own inferences and analogies, fostered their own ideas." (Carr 2010, 64-65; my emphasis)

What is so valuable about deep reading and deep thinking is that they provide an opportunity for people to exercise their own creativity to formulate thoughts that are uniquely theirs. Accordingly, reading (and thinking) is not only about receiving information and/or knowledge from texts; reading (and thinking) ought to "[inspire] new insights, associations, and perceptions, sometimes even epiphanies" (Carr 2010, 74). Carr's foregrounding of creativity, individuality (i.e. thoughts that are unique to the person) and authenticity (i.e. thoughts that belong to them) should be familiar, because they are the basic values embodied in the image of the expressive self, which, again, is a notion I borrow from Taylor (1989). The notion of the expressive self can be viewed as the Romanticist reaction against the rise of the disengaged self: while the disengaged self places (instrumental) rationality at the core of its ideal, the expressive self rejects the disengaged self's lone emphasis on (procedural) reason, and embraces a broader notion of nature as inner voice, which takes seriously one's feeling as a guide to their flourishing. As Taylor summarises, the expressive self is captured by Romanticism's doctrines of the rights of the individual, the power to creative imagina-

\footnotetext{
${ }^{10}$ The worry over the fragmentation of text can also be found in Carr's discussion of the Internet's impacts on writing. In The Shallows, he compares printed books with ebooks, and he states that printed books differ from ebooks in that they are finalised. The finality of printed books, he argues, compels authors to perfect their works to ensure that they truly (re)present their own thoughts before they are being published. He argues that this mentality of perfection (and, relatedly, being truthful to oneself) has dissipated in ebooks because ebooks are viewed as a process, i.e. something editable by authors even after they are released (Carr 2010, 107-108)
} 
tion and the importance of feeling for the search of a meaningful life. ${ }^{11}$ In short, Carr's criticism is grounded in the expressive self.

Carr's criticism of the Internet focuses only on its impacts on our cognitive capacity and leaves out our emotional capacity. In this respect, Sherry Turkle's Alone Together: Why We Expect More from Technology and Less from Each Other (2011) is a suitable complement to Carr's criticism, as it concerns with the impacts of digital media on our emotional capacity. In her discussion, Turkle attempts to show that digital media has bred an equally shallow emotional mind. ${ }^{12}$ And, like Carr, Turkle expresses worry over the loss of richness of the mind, individuality and authenticity with the rise of habitual digital connection. Turkle's criticism of digital media, I think, can too be viewed as being grounded in the expressive self.

Turkle notes that digital media affords a new understanding of distance and time: distance is now defined by connectivity and availability but not by physical space (Turkle 2011, 155-156); time has also received a new meaning as digital media allows people to layer multiple activities on a single temporal unit (Turkle 2011, 164). The new understanding of distance (or space) and time, in turn, makes possible "life mix", i.e. a new form of life that is "the mash-up of what you have on- and offline" (Turkle 2011, 160). "Life mix", in Turkle's view, is dangerous because it causes distraction and leads to a loss of attention (Turkle 2011, Chapter 8 \& 14). Distraction and the loss of attention in "life mix", however, are unlike what Carr has described. They are not cognitive, but emotional. By living in different (on- and offline) lives in simultaneity, people's attention-in terms of emotional involvement and attachment-is distributed across different lives they have simultaneously, and thus attention to each life is inevitably thinned out. The result, therefore, is a loss of richness in emotional involvement and attachment to specific persons and/or situations.

Turkle also voices worry over the changing conditions of personal engagement that come with constant connectivity. Digital media allows young people (and adults) to always stay connected to their parents and peers. Constant connectivity, however, has the side-effect of removing the private space from individuals, which is essential for them in their individual development. In effect, she argues that digital media favours "the collaborative self" of which the self only feels emotionally complete when it is connected (Turkle 2011, 171-179). In short, the (internal) richness of individuals has given way to (external) connectivity in a digitally-mediated life. And, the worry over the rise of "the collaborative self" should sound familiar. Indeed, Turkle's worry compares nicely with Shirky's praise of the imperative of (inter)activity, which is grounded in the idea of quasi-subject. Like Shirky, Turkle sees an emergence of quasi-subject with the rise of social media. Unlike Shirky, however, she foregrounds the loss of individuality and authenticity from becoming the collaborative self and deems that to be undesirable.

Finally, although "life mix" can expand people's ability to experiment with their identity in their (online) lives, digitally enabled "life mix", paradoxically, can also hamper the authenticity of their (offline) identity. Indeed, Turkle agrees that online worlds allow people to rework their identity and practise new identity in their online lives (see, e.g. Turkle 2011, 179-182, 189-194, 211-224), but she also warns that social media-the new, and now also the most prominent, space for (online) identity construction-is significantly different. In social media, users are compelled to present themselves in a simplified manner (Turkle 2011, 179-186). In this respect, social media also compels us into editing away our authenticity, at least, for our online lives. Yet, authenticity is at stake not only when people are using social media, but it is more so when their (new) identities in online worlds come to live on their own terms and replace their offline identities (Turkle 2011, Chapter 11).

\subsection{The Hive Mind}

While Carr and Turkle set to examine how digital media has changed the way we think and feel, and whether the new mind arises from the changes is desirable or not, Jaron Lanier examines the impacts of digital media on our self-understanding more generally in You Are Not a Gadget: A Manifesto (2010) in which he discusses how digital media influences the way we perceive ourselves as human beings. ${ }^{13}$

Lanier sets to criticise Web 2.0 in his book. He argues that the advent of Web 2.0 has led to a "reduced expectation of what a person can be, and of who each person might become" (Lanier

\footnotetext{
${ }^{11}$ See, Wong (2010).

${ }^{12}$ In Alone Together, Turkle discusses the impacts of both sociable robots and digital media on our emotional capacity. In this section, I only look at Part II of Alone Together (esp. Chapter 8-14), where she voices her concerns over the impacts of digital media on our emotional capacity.

${ }^{13}$ Lanier, however, not only discusses the impacts of digital media on our self-interpretation and self-understanding; he also discusses its impacts on economy (Lanier 2010, Chapter 4-8) and culture (Lanier 2010, Chapter 9-11). But, I will only focus on his view on how Web 2.0 has changed our self-interpretation and self-understanding in this section.
} 
$2010,4)$. And, he also argues that the reduced expectation is a result of modelling and designing Web 2.0 on the basis of the hive mind, that is-to see "a random crowd of humans [as] an organism with a legitimate point of view" (Lanier 2010, 4). According to Lanier, Web 2.0 has crystallised the idea of the hive mind by encouraging people to see "the Internet as a whole is [being] alive and [...] a superhuman creature" (Lanier 2010, 14). Lanier's worry, in other words, is that there is, or will be, a replacement of "individual intelligence" by "the pack mentality" (Lanier 2010, 5). For him, Web 2.0 has quickened and amplified such a replacement by heightening the importance of non-human and/or non-personal intelligence (of the crowd) and degrading the wholeness of human being and person.

In essence, Lanier's criticism of Web 2.0 is an argument against anti-humanism, i.e. the view that there is nothing unique about human beings in comparison to other entities, and antipersonalism, i.e. the view that there is nothing unique about a specific person in comparison to other persons (or, things). In Lanier's own terms, his argument is against what he called "computationalism", i.e. the view that "the world can be understood as a computational process, with people as subprocesses" (Lanier 2010, 153). Against anti-humanism, anti-personalism, and computationalism, Lanier curiously tries to revive the uniqueness of humanity and personhood by imbuing some mystical qualities on human beings and being-a-person. For instance, he attempts to argue that the value of information necessarily rests on personal experience (Lanier 2010, 28-29); and, he also attempts to argue that human consciousness is uniquely human (as a personal phenomenon) which cannot be replicated with any computational process or to be found in the hive mind (Lanier 2010, 29-44, 153-157). In doing so, Lanier is, in fact, attempting to reassert the primacy of humanity and personhood against the non-human and the impersonal.

For Lanier, the hive mind (or, dehumanisation, depersonalisation, and computationalism) is problematic because he believes it will incur a loss of personal creativity, as people are no longer "being treated as the source of their own creativity" (Lanier 2010, 16; my emphasis; also see, Lanier 2010, Chapter 9). At the same time, he also believes that it will incur a loss of diversity by encouraging and compelling people to tailor themselves for the crowds and to disregard personal flavours (Lanier 2010, Chapter 10).

Now, I think, it should be relatively clear that Lanier's criticism of Web 2.0, like Carr's and Turkle's, is also grounded in the expressive self. His criticism foregrounds the importance of individuality and the evils of the hive mind, i.e. the loss of individuality and authenticity, especially in terms of the wholeness of human being and person. He also emphasises the significance of (artistic) creativity and the importance of viewing creativity as a personal quality. Yet, the most telling part of Lanier's criticism is his attempt to imbue mystical qualities on human being and personhood. Of course, it does nothing by itself to tell us what the normative and axiological foundation of his criticism of Web 2.0 is, but it does show that his criticism is not based on the idea of the subjects as autonomous, rational beings.

\subsection{Minds of the Future}

Appraisals of Web 2.0 in the neurological turn are mostly negative. This is predictable because an alteration of our cognitive and emotional mind and of who we are seems to pose a greater and more immediate danger than alterations of our surroundings. Still, it is possible to find a few authors who hold a less hostile and more positive view towards the (potential) changes in our brain. One such example is Nick Bilton's I Live in the Future \& Here's How It Works: Why Your World, Work, and Brain Are Being Creatively Disrupted (2010). Bilton's view is particularly interesting because he himself belongs to the group of people who grew up with digital media, i.e. the digital natives, and his view is presumably articulated from such a perspective (Shafer 2010). In this respect, Bilton's view on digital media can be seen a useful approximation of the view held by digital natives, who take the impacts of digital media not so much as changes but more so as givens.

As the subtitle of Bilton's book suggests, his discussion does not only limit to digital media's impacts on our brain. However, I will only focus on Bilton's discussion of the new state of mind emerging from the use of digital media, which, in turn, can be seen as a response to the pessimistic views held by Carr, Turkle, Lanier and the like. A contrast between Bilton's (more) positive view and the pessimistic views previously analysed should help to illuminate the different normative and axiological foundations of the two sides.

Bilton has responded to the worry raised by Carr over the possibility of distraction and the loss of attention caused by the habitual use of the Internet. In his response, Bilton accepts Carr's ideas that (i) reading on screen (or, surfing the Internet) and reading on paper are phenomenologically different, and (ii) that the Internet, because of those characteristics identified by Carr, is distracting and causing a loss of attention, and, finally, (iii) that deep reading and deep thinking as Carr char- 
acterised are unlikely to happen in an online environment (Bilton 2010, Chapter 5). ${ }^{14}$ However, Bilton argues that none of those 'changes' should be viewed as devastative to us; he argues that there are other cognitive skills, e.g. multi-tasking, which are equally_or, even, more-important, and deep reading and deep thinking are just few of the many cognitive skills available (Bilton 2010, Chapter 7). He writes matter-of-factly that the shift to multi-tasking is natural because it is merely a (new) mechanism to cope with the changing nature of our information environment, which is analogous to people's learning of (deep) reading for acquiring information in books and long-form narratives in the past (Bilton 2010, Chapter 7). He holds the same view towards social media (and so the hive mind), too. Unlike Lanier, who sees the hive mind as problematic, Bilton takes the wisdom of the crowd made possible by social media merely to as a (new) mechanism to cope with information (over-)abundance, which, according to Bilton, is simply a given for him and digital natives (Bilton 2010, Chapter 3).

Although Bilton does not make explicit what is of value about digital media, his rebuttal to Carr's criticism and Lanier's criticism is instructive; he sees digital media to have provided people new mechanisms to cope with the new fast-paced and information-rich environment, which requires rapid and nimble responses from individuals. This places Bilton's view of digital media fittingly with the reflexive self, which stresses the importance of individuals' (cognitive) capabilities to construct their self-narratives via lifestyle choices and life-planning. Indeed, for Bilton, the new mechanisms are not to be afraid of, but are to be championed, because they are only a "constructive way [for ourselves and our brain to adapt] to this new online world" (Bilton 2010, 136; my emphasis). In short, multitasking and the wisdom of the crowd are good and desirable because they are regarded as indispensible to the construction of self-narratives in a digitally-mediated world.

Before moving to the next section, I should mention that the foregoing sections do not intend to suggest which of the views on Web 2.0 are more satisfactory. The aim of my (re)interpretation is only intended to uncover the normative and axiological foundation of the selected views, and thus to reveal why and how digital media and digitally-mediated practices are judged by people in a specific way. Although the foregoing analysis does not tell us which views are better, or what our judgements of digital media and digitally-mediated practices ought to be, I think it does allow us to make better judgements on digital media and digitally-mediated practices, as it informs us how our judgements should be made, or so I argue in the next section.

\section{Who Should We Be in a Digitally-Mediated World?}

My selective history of Web 2.0's axiologies is by no means an exhaustive representation of the notions of the self and the embodied ideals (or, the views of the good life) in all judgements on digital media and digitally-mediated practices, but I think my (re)interpretation has illustrate the role of the self (e.g. the disengaged self, the expressive self and the reflexive self) in grounding different judgements of digital media and digitally-mediated practices; and, in turn, it has provided strong support to the idea that the self is the normative and axiological foundation for determining whether digital media is considered to be good for us or not. It, I think, has an important implication to normative analysis of digital media, as well as our own judgements on digital media and digitallymediated practices, because it entails that any normative judgements of digital media and digitallymediated practices cannot be made without also invoking some notions of the self, even if we have already been doing so implicitly.

Accordingly, a specific pattern of normative judgments of digital media and digitally-mediated practices, which can often be found in both scholarly and popular discourse, will necessarily be incomplete and insufficient. The pattern of normative judgements I have in mind has the following form: ${ }^{15}$

- (J1i) Digital media T promotes some values V1...n.

- (J2i) V1...n are bad/undesirable (for individuals) morally and/or prudentially.

- (JCi) T is bad/undesirable (for individuals) morally and/or prudentially. Or,

\footnotetext{
${ }^{14}$ It is not entirely true to claim that Bilton believes deep thinking cannot happen in an online environment, as he states that "[s]ome say the Internet and multitasking with media are making our brains into one big distraction zone incapable of handling complex ideas or long-form narrative. I don't agree" (Bilton 2010, 197; my emphasis). But, it is helpful to point out that what he means by 'complex ideas' and 'long-form narrative' are very different from what is described by Carr. Particularly, his ideas of 'complex ideas' and 'long-form narrative' appear to be about multiple and constant sensual stimulations.

${ }^{15}$ It is a simplified formulation of the pattern of normative judgements. Particularly, it is worth pointing out that $T$ can promote (or demote) $\mathrm{V} 1 \ldots . \mathrm{n}$ indirectly through encouraging (or discouraging) some behaviours and practices U1...n that promote (or demote) V1...n. Since this addition does not affect my discussion of this pattern, I shall use the simplified formulation to avoid unnecessary complication.
} 
- (J1ii) Digital media T demotes some values V1 ...n.

- (J2ii) V1 ...n are good/desirable (for individuals) morally and/or prudentially.

- (JCii) T is bad/undesirable (for individuals) morally and/or prudentially. ${ }^{16}$

This pattern of normative judgements can be found, for example, in Keen's and Carr's criticisms. For instance, Keen argues that Web 2.0 is bad (i.e. (JC)), because it promotes amateurism (i.e. (J1)), and he regards amateurism to be undesirable (i.e. (J2)). Similarly, Carr argues that the habitual use of the Internet reduces our capacity to focus and concentrate (i.e. (J1)), and he sees this capacity to be essential for a good life (i.e. (J2)). So, he concludes that the habitual use of the Internet is bad (i.e. (JC)).

Here, my claim is not that digital media does not promote or demote certain values, or that digital media is neutral. I believe we have already seen with sufficient evidence that digital media does promote (or demote) certain values. It is also not my intention to contest the goodness (or badness) of specific values promoted (or demoted) by digital media. My focus here is on the form of this pattern of normative judgements, and my claim is that even if (J1) and (J2) are true and (JC) does follow, normative judgements with this pattern are always incomplete and insufficient because they have failed to acknowledge (or, at least, to make explicit) the fact that they are grounded in a specific notion of the self. This, ultimately, also renders normative judgements with this pattern indecisive and ineffective, because without settling on a specific view of the self, discussants are only affirming their own views of what is of value and ignoring the possibility that others may not share their views. In other words, they are (or, at least, risk) talking passed each other.

If my argument against the completeness and sufficiency, and thus the decisiveness and effectiveness, of this pattern of normative judgements is sound, then we have to examine various notions of the self more carefully before we can meaningfully engage with the values and disvalues of digital media. After all, when what is of value is in question, merely insisting something is of value is not going to take us very far. Particularly, as I have attempted to show in the previous sections, the positive and negative views on digital media appear to be originated from different notions of the self: those who hold the modern notions of the self (i.e. the disengaged self and the expressive self) tend to judge digital media and digitally-mediated practices negatively, whereas those who hold the late modern notion of the self (i.e. the reflexive self) tend to judge them positively. If it is indeed so, instead of (only) arguing for or against digital media on the basis of the values it promotes or demotes, we should first examine why those values are of value, and whether they are still of value by redirecting ourselves to the question: which notion(s) of the self we should strive for in our digitally-mediated world? Or, in other words, who should we be in our digitally-mediated world? ${ }^{17}$

A shift towards the question concerning who we should be will also be significant to our pursuit of an informed public discourse on digital media and digitally-mediated practices too. Particularly, as our judgements of digital media are based on the notions of the self we hold, our public discourse cannot afford to ignore them if we want it to be a genuinely informed public discourse. At the same time, when researchers and critics are recommending some human-digital media relations to the public, their recommendations can be reinforced by clearly showing why those humandigital media relations should be held by the public, i.e. by showing those human-digital media relations are prescribed (or, at least, favoured) by the notions of the self the people hold. Alternatively, by showing why and how some notions of the self cannot adequately answer the question 'who we should be in the digitally-mediated world', we can also demonstrate to the public why and how certain normative judgements on digital media and digitally-mediated practices are wrongheaded, as well as convince them to follow our recommendations.

\footnotetext{
${ }^{16}$ This pattern, of course, can also be formulated differently to argue in favour of digital media. Accordingly, the pattern of normative judgements will be the following:

(J1iii) Digital media T promotes some values $\mathrm{V} 1 \ldots \mathrm{n}$.

(J2iii) V1...n are good/desirable (for individuals) morally and/or prudentially.

(JCiii) $\mathrm{T}$ is good/desirable (for individuals) morally and/or prudentially.

Or,

(J1iv) Digital media T demotes some values $\mathrm{V} 1 \ldots . \mathrm{n}$.

(J2iv) $\mathrm{V} 1 \ldots \mathrm{n}$ are bad/undesirable (for individuals) morally and/or prudentially.

(JCiv) $\mathrm{T}$ is good/desirable (for individuals) morally and/or prudentially.

Regardless of the formulation, my criticism applies so long as the pattern of normative judgements in question does not make explicit its normative and axiological foundation, namely what makes the values $\mathrm{V} 1 \ldots . \mathrm{n}$ valuable.

${ }^{17}$ Cf. Winner (1996). Winner arrives at the same conclusion from a different argument. In his article, Winner argues against the focus on the use of information technology, i.e. "what to do [with information technology]", and urged researchers to refocus on the question on "who to be [with information technology]" (Winner 1996, 71).
} 
Unfortunately, I do not think there is a definitive answer to the question 'who we should be in our digitally-mediate world'. However, my selective history of Web 2.0's axiologies should have at least served to make explicit various notions of the self lie underneath the positive and negative views on digital media and digitally-mediated practices, and thus it should enable us to better assess them by showing explicitly why digital media and digitally-mediated practices are of value. For example, traditional cultural institutions and experts (in Keen's criticism), participation and sharing (in Shirky's account), deep reading and deep thinking (in Carr's criticism), emotional involvement and attachment (in Turkle's criticism), the wholeness of humanity and personhood (in Lanier's criticism) and multi-tasking and the wisdom of the crowd (in Bilton's account) are of value because they are constitutive of specific ways of self-interpretation and self-understanding. Uncovering the normative and axiological foundation of our judgements should also enable us to better judge digital media and digitally-mediated practices, because it can advance our own normative judgements of digital media and digitally-mediated practices by opening up the space for a re-appropriation and fusion of various notions of the self.

Yet, the hard question of 'who should we be in our digitally-mediated world?' remains. In the remainder of this article, I will try to shed light on the answer(s) to this hard question. However, I do not think a definitive answer can be (easily) given. So, instead of giving an answer to the question, I should only consider how we might answer it.

\subsection{Ess on Digital Media and the Self}

(Digital) media is part of the background for our self-understanding and self-interpretation as well (see, e.g. Ess 2010, 2011; Bakardjieva \& Gaden 2012). If this is so, understanding the interactions between digital media and the self is paramount for our answering of the question of 'who should we be in our digitally-mediated world?', because digital media too (co-)shapes our selfinterpretation and self-understanding and (dis)favours certain notions of the self.

In his recent works, Charles Ess (2010; see also Ess 2011) has systematically explored the interactions between digital media and the self. Drawing from communication theory, information ethics and phenomenology, he argues that different modalities of communication (i.e. orality, literacy, print and secondary orality of digital media), together with the different values and skill sets associated with them, are strongly correlated with different ways of self-interpretation and selfunderstanding. In a nutshell, he points out that literacy and print are strongly correlated to an individualistic understanding of the self (Ess 2010, 106-108), whereas secondary orality of digital media is strongly correlated to a distributed (or relational) understanding of the self (Ess 2010, 110111). More specifically, Ess conceptualises the self arising from secondary orality of digital media with the idea of "smeared-out self", i.e. "[a self] distributed across CMC networks via multiple means of communication (SMS, social networking sites, micro-blogging, email, etc.) that thereby represent hundreds, if not thousands, of simultaneous but potential relationships/engagements that [individuals] realise one at time" (Ess 2010, 111).

Ess's analysis of the interactions between digital media and the self is instructive, as it illustrates how digital media can affect our self-interpretation and self-understanding by enabling (or, indeed, compelling) individuals to move away from an individualistic understanding of the self, which are characteristic of the modern notions of the self (i.e. the disengaged self and the expressive self) and (re)turn to a distributed/relational understanding of the self, which are more characteristic of the self in late modern societies. Indeed, it is plausible to conclude from this that digital media actually favours the late modern self and disfavours the modern self. Recognising this dynamic is important, as it provides hints of why certain arguments for (or against) digital media and digitally-mediated practices become (un)persuasive, e.g. Shirky's imperative of (inter)activity is persuasive because it adheres to an interpretation and understanding of the self that is favoured by digital media. This, in turn, should make us aware of the (un)persuasiveness of the arguments actually comes with the rise of digital media, and thus they should not be taken for granted.

More importantly, Ess argues that it is the values (and skill sets) of the modern notions of the self, especially of the disengaged self (e.g. knowledge, autonomy, equality, impartiality and tolerance), that buttress the idea of democracy. He notes that without the values (and skill sets) of the modern notions of the self enabled by literacy and print, there is a risk of (re)turning to authoritarianism. In response to this risk, Ess proposes we should see secondary orality of digital media not as a replacement of literacy and print, but only as a compliment to them. It is not my intention to argue for or against Ess's proposal here, but his proposal has provided us an important insight for answering the question of 'who should we be in our digitally-mediated world?', that is-the answer to this question cannot be merely personal because it also depends on the type(s) of society we want to live in. For instance, if we want to live in a democratic society, which, according to Ess, is 
strongly correlated to (or, in effect, only made possible by) the values and skill sets of the modern self, then we must somehow incorporate (the values and skill sets of) the modern self in our answering of the question. Yet, to realise the type(s) of society we want to live in is not merely a personal matter, it is also a socio-political matter too. In short, our ideas of society also contribute to our answering of the question as well.

\subsection{In Pursuit of the Self in a Digitally-Mediated World}

Ess's analysis nicely shows that an answer to the question of 'who we should be in our digitally media world?' requires us to reflect on the type(s) of society we want to live in. There is, however, another lesson from Ess's analysis of the interactions between digital media and the self: if digital media does interact with the self and (dis)favours some notions of the self, then there is also a need to (re)examine to what extent various notions of the self are still plausible with the rise of digital media. Or, to put it differently, we must (re)examine how the rise of digital media affects the options we have for answering the question.

Recently, Mark Deuze $(2010,2011,2012)$ has argued for an ontological turn in (digital) media studies. He argues that digital media has become so pervasive and ubiquitous to the extent that it has also become the building blocks of our experience in everyday life and the structure of our meaningfulness. Deuze's claim is not only that we encounter and use a variety of digital media in our everyday life, but that we cannot experience our everyday life and make sense of ourselves and the world around us without them. In other word, Deuze's claim is that digital media can no longer be seen as something extrinsic to our experience and sense-making, but it must be taken as intrinsic to them. Accordingly, digital media is a constitutive part of our ontology, as Deuze has put it, "we lived in, rather than with, media-we are living a media life" (Deuze 2011, 138; see also, Deuze 2012). Of course, Deuze's attempt to (re)conceptualise (digital) media as a constitutive part of our ontology is not uncontroversial and therefore requires further scrutiny. However, if Deuze is right, then it entails digital media is at the same time constitutive of our self-interpretation and selfunderstanding, too; since we must then always interpret and understand ourselves and the world around us through digital media. ${ }^{18}$

So construed, and if Deuze is right, any plausible answer to the question of 'who we should be in our digitally-mediated world?' must make room for a constitutive relation between digital media and the self. In other words, they must be able to account for the role of digital media as a constitutive part of our self-interpretation and self-understanding. This requirement, in turn, might rule out some notions of the self as a plausible answer to the question.

For instance, modern notions of the self (e.g. the disengaged self and the expressive self) appear to be particularly at stake. As Peter-Paul Verbeek (2009) has convincingly argued in the field of philosophy of technology, modern notions of the self distinguish too sharply between the subject and objects (and, between persons and things) ontologically, and that such a rigid ontological separation of the subject from objects (and of persons from things) inevitably bars them from taking objects and things to be morally significant, because morality is then confined entirely to a specific ontological domain, i.e. the subject's and human beings' domain, where objects and things are excluded entirely. Although Verbeek's discussion mainly focuses on the morality of objects and things, his argument on the incapability of modern notions of the self to take objects and things to be morally significant can be easily translated into the present context: if modern notions of the self draw a sharp boundary between the self (i.e. the subject) and digital media (i.e. the object), and they are seen as belonging to two radically distinct ontological domains, then digital media cannot be taken as constitutive of the self because of their ontological differences. In this respect, modern notions of the self-or, for that matter, any notion of the self that presumes a sharp ontological difference between the subject and objects (or persons and things)—cannot provide a plausible answer to the question of 'who we should be in our digitally-mediated world?'. ${ }^{19}$

\footnotetext{
${ }^{18}$ Although Ess's analysis shows that (digital) media does interact with the self, it is less clear if Ess is going to accept Deuze's more radical conclusion that digital media is constitutive of the self. Indeed, there are two ways to conceive the interactions between digital media and the self, namely (i) it can be viewed as instrumental for the (be)coming of a specific notion of the self, e.g. literacy and print enable the rise of an individualistic understanding of the self, and secondary orality of digital media enables the rise of a distributed/relational understanding of the self, and (ii) it can be viewed as constitutive of a specific notion of the self, as Deuze suggests.

${ }^{19}$ To overcome "the humanist bias of ethics" (Verbeek 2009, 245-248), Verbeek argues for an ethics of design and ethics of technological mediation, where the former examines design as a practice of materialising morality, the latter examines the moral nature of technological mediation (Verbeek 2009, 255-260). Although I am generally sympathetic to Verbeek's approach, I worry that his emphasis on materiality and technological mediation in lieu of the language of morality has an unintended consequence of cutting the public off from moral deliberation. Particularly, we should be aware of the fact that
} 
The implausibility for modern notions of the self as an answer to the question, however, seemingly presents us with a predicament: even if we see criticisms of digital media and digitallymediated practices arrived from modern notions of the self as real, e.g. the devaluing of scientific standards and scientific rationality, the loss of deep reading, deep thinking, and deep emotional involvement and attachment, etc., modern notions of the self have lost their normative and axiological grounds to assert their importance. Alternatively, consider Ess's proposal to preserve the values and skill sets of modern notions of the self for their importance to democratic society; it seems to be difficult, if not impossible, to do so if modern notions of the self cease to be a plausible answer to the question.

Where, then, does this predicament lead us? Does it mean that we must happily accept the 'loss' of the values and skill sets of modern notions of the self, and view it as an emancipation from them? Here, it is helpful to remind ourselves that the self is not simply fixed. Indeed, the exercise of (re)interpretation I have performed in this article has not only shown how various notions of the self are at work in our judgements of digital media and digitally-mediated practices. At the same time, it has also uncovered the normative and evaluative resources we can (re-)appropriate in our pursuit of the notion(s) of the self that might serve as a plausible answer to the question. In other words, even if modern notions of the self alone are no longer plausible as an answer to the question of 'who we should be in our digitally-mediated world?', it does not rule out the possibility of creative (re-)appropriation and fusion of the values and skill sets embodied by them. However, with the continuing development of digital media, I contend that the question will remain as an open question that affords no definitive answer. Yet, the key to answer this question, I think, lies in our effort to disclose various notions of the self and to creatively (re-)appropriate and fuse them.

Finally, my discussion cannot be complete without also briefly mentioning the role(s) played by the government and policy-makers in shaping our digitally-mediated world through various agendasettings and policies on the development and diffusion of digital media in our society, as the government and policy-makers are essentially promoting some ideals through their agendas and policies. If we, i.e. the public, are to answer the question of 'who we should be' by ourselves, instead of having an answer imposed on us, then the government and policy-makers ought to open up their agendas and policies for public discussion. Of course, I am not suggesting the government and policy-makers must not maintain any ideal in their agendas and policies, which, I believe, is impossible, but they ought to be transparent with those ideals behind their agendas and policies, because it is only then the public can truthfully assess the agendas and policies, and compare them with their own ideals.

\section{Conclusion}

The main goal of this article is to offer a better understanding of the normative and axiological foundation of our judgements on digital media and digitally-mediated practices. I have examined the discussions focus on the impacts of Web 2.0 on society-at-large (i.e. Keen's The Cult of Amateur and Shirky's Here Comes Everybody and Cognitive Surplus) in the first section of this article; and then, I have examined the discussions focus on the impacts of digital media on our brain, mind, cognition and selfhood (i.e. Carr's The Shallow, Turkle's Alone Together, Lanier's You Are Not a Gadget and Bilton's I Live in the Future \& Here's How It Works). Throughout my analysis, I have attempted to show that the different views are, ultimately, grounded on different notions of the self.

Acknowledging the self as the normative and axiological foundation of our normative judgements on digital media and digitally-mediated practices means that we have to make explicit the notion(s) of the self in our own normative judgements, especially if we are to properly assess and engage with them; and, we have to make explicit the notion(s) of the self in our own normative judgements, because, otherwise, our judgements will be incomplete and insufficient, and thus indecisive and ineffective. Moreover, taking seriously the idea that the self is the normative and axiological foundation of our normative judgements on digital media and digitally-mediated practices also means that we should redirect our attention from (dis)values of digital media and digitallymediated practices to the question of 'who we should be in our digitally-mediated world?', as merely talking about the values of digital media and digitally-mediated practices will bound to be inadequate without at the same time showing why those values are of value at all. In other words, I have shown that normative analysis of digital media must begin with questions about the self, especially the question about who we should be and who we can be in a digitally-mediated world.

(ethics of) design is monopolised by those who are involved in the process of design and not open to the public. For a discussion of this issue, see Wong (2011). 
Finally, I end this article by looking at what it takes to answer the question 'who we should be in our digitally-mediated world?'. Although I cannot offer a definitive answer to this question, I have outlined two considerations for any attempt to answer it. Firstly, I noted this question cannot only be taken as a personal question, because our answers to it depend crucially on the type(s) of society we want to live in. This question, therefore, is also a socio-political question. Secondly, I noted that recent research in (digital) media theory and philosophy of technology have convincingly argued that digital media is (or has become) a constitutive part of our self-interpretation and selfunderstanding. If this line of thinking is correct, then our answers to the question must make room for a constitutive role of digital media in our self-interpretation and self-understanding. Accordingly, some notions of the self (e.g. modern notions of the self) will inevitably fall short as an answer to the question. Yet, it does not mean that we cannot creatively re-appropriate and fuse the values (and skill sets) of different notions of the self I have discussed; however, it does mean that we need to pay more attention to the kind(s) of the self we should be in our digitally-mediated world. In short, we need to (re-)open the question of 'who we should be' in normative analysis of digital media.

\section{References}

Bakardjieva, Maria and Georgia Gaden. 2011. Web 2.0 Technologies of the Self. Philosophy \& Technology 25 (3): $399-413$. Beck, Ulrich and Elisabeth Beck-Gernsheim. 2002. Individualization: Institutionalized Individualism and Its Social and Political Consequences. London: Sage.

Beck, Ulrich, Wolfgang Bonss and Christoph Lau. 2003. The Theory of Reflexive Modernization: Problematic, Hypotheses and Research Programme. Theory, Culture \& Society 20 (2): 1-33.

Beer, David and Roger Burrows. 2007. Sociology and, of and in Web 2.0: Some Initial Considerations. Sociological Research Online 12 (5). Accessed December 27, 2012. http://www.socresonline.org.uk/12/5/17.html

Benkler, Yochai. 2006. The Wealth of Networks: How Social Production Transforms Markets and Freedom. New Haven: Yale University Press.

Bilton, Nick. 2010. I Live in the Future \& Here's How It Works: Why Your World, Work, and Brain are Being Creatively Disrupted. New York: Crown Business.

Carr, Nicholas. 2008. Is Google Making Us Stupid. The Atlantic (July/August). Accessed June 8, 2012. http://www.theatlantic.com/doc/200807/google

Carr, Nicholas. 2010. The Shallows: What the Internet is Doing to Our Brains. New York: W.W. Norton.

Deuze, Mark. 2009. Media Industries, Work and Life. European Journal of Communication, 24 (4): 1-14.

Deuze, Mark. 2011. Media Life 2.0. Media, Culture \& Society 33 (1): 137-148.

Deuze, Mark. 2012. Media Life. Cambridge: Polity Press.

Ess, Charles. 2010. The Embodied Self in a Digital Age: Possibilities, Risks, and Prospects for a Pluralistic (Democratic/Liberal) Future? Nordicom Information 32 (2/3): 105-118.

Ess, Charles. 2011. Self, Community, and Ethics in Digital Mediatized Worlds. In Trust and Virtual Worlds: Contemporary

Perspectives, edited by Charles Ess and May Thorseth, 3-30. New York: Peter Lang.

Frick, Marie-Luisa and Andreas Oberprantacher. 2011. Shared is not Yet Sharing, Or: What Makes Social Networking Services Public? International Review of Information Ethics 15: 17-23.

Fuchs, Christian, Wolfgang Hofkirchner, Matthias Schafranek, Celina Raffl, Marisol Sandoval and Robert Bichler. 2010. Theoretical foundations of the Web: Cognition, Communication, and Co-operation: Towards an Understanding of Web 1.0, 2.0, 3.0. Future Internet 2 (1), 41-59.

Giddens, Anthony. 1991. Modernity and Self-Identity: Self and Society in the Late Modern Age. Stanford: Stanford University Press.

Glynos, Jason, David Howarth, Aletta Norval and Ewen Speed. 2009. Discourse Analysis: Varieties and Methods. ESRC National Centre for Research Methods Review Paper. Accessed June 8, 2012. http://eprints.ncrm.ac.uk/796/

Keen, Andrew. 2007. The Cult of Amateur: How Today's Internet is Killing Our Culture. New York: Doubleday/Currency.

Lanier, Jaron. 2010. You Are Not a Gadget: A Manifesto. London: Allen Lane.

Last, Jonathan V. 2010. Future Guy. The Weekly Standard 16 (8). Accessed June 8, 2012. http://www.weeklystandard.com/articles/future-guy_513321.html

Leadbeater, Charles. 2008. We-Think. London: Profile.

Lessig, Lawrence. 2007. Keen's "The Cult of the Amateur": BRILLIANT! Lessig Blog 31 May 2007. Accessed June 8, 2012. http://lessig.org/blog/2007/05/keens_the_cult_of the_amateur.html

Lovink, Geert. 2010. MyBrain.net: the Colonization of Real-time and Other Trends in Web 2.0. Eurozine, 18 March 2010. Accessed June 8, 2012. http://www.eurozine.com/articles/2010-03-18-lovink-en.html

Lovink, Geert. 2011/2003. My First Recession: Critical Internet Culture in Transition. Amsterdam: Institute of Network Cultures.

Shafer, Jack. 2010. Digital Native Calms the Anxious Masses. Slate 13 September, 2010. Accessed June 8,2012 http://www.slate.com/id/2267161

Shirky, Clay. 2009. Here Comes Everybody: How Change Happens When People Come Together. London: Penguin.

Shirky, Clay. 2010. Cognitive Surplus: Creativity and Generosity in a Connected Age. London: Allen Lane.

Tapscott, Don and Anthony D. Williams. 2006. Wikinomics: How Mass Collaboration Changes Everything. New York: Portfolio.

Tapscott, Don and Anthony D. Williams. 2010. Macrowikinomics: Rebooting Business and the World. New York: Portfolio.

Taylor, Charles. 1989. Sources of the Self: The Making of Modern Identity. Cambridge: Cambridge University Press. 
Thierer, Adam. 2011. The Case for Internet Optimism, Part 1: Saving the Net from Its Detractors. In The Next Digital Decade: Essays on the Future of the Internet, edited by Berin Szoka and Adam Marcus, 57-87. Washington: TechFreedom.

Turkle, Sherry. 2011. Alone Together: Why We Expect More from Technology and Less from Each Other. New York: Basic Books.

Van Dijck, José and David Nieborg. 2009. Wikinomics and Its Discontents: A Critical Analysis of Web 2.0 Business Manifestos. New Media \& Society 11 (5): 855-874.

Verbeek, Peter-Paul. 2009. Cultivating Humanity: Towards a Non-Humanist Ethics of Technology. In New Waves in Philosophy of Technology, edited by Jan Kyrre Berg Olsen, Evan Selinger and Søren Riis, 254-260. New York: Palgrave Macmillan.

Winner, Langdon. 1996. Who Will We Be in Cyberspace? Information Society 12 (1): 63-72.

Wong, Pak-Hang. 2010. Information Technology, the Good and Modernity. In Thinking Machines and the Philosophy of Computer Science: Concepts and Principles, edited by Jordi Vallverdú, 223-237. Hershey: Information Science Reference.

Wong, Pak-Hang. 2011. Technology, Recommendation and Design: On Being a 'Paternalistic' Philosopher. Science and Engineering Ethics. Accessed February 8, 2013. doi: 10.1007/s11948-011-9288-9.

\section{About the Author}

Pak-Hang Wong

is a Research Fellow at the Institute for Science, Innovation and Society (InSIS) and Oxford Uehiro Centre for Practical Ethics, University of Oxford. He works primarily on philosophy and ethics of technology, but he also works on practical ethics, moral and political philosophy, social theory, (digital) media studies, and science and technology studies. 